\title{
Ambiguous loss and incomplete abduction narratives in Kosovo
}

\author{
Laura Kajtazi-Testa \& Christopher J Hewer
}

Kingston University

\begin{abstract}
Ten mothers of men and boys who were abducted and listed as missing during the war in Kosovo in 1998/99 were interviewed in Kosovo in the spring of 2012. Although the missing are presumed dead by the authorities, the mothers continue to live in a state of emotional ambiguity where a presumption of death is balanced with the hope of being reunited. In the absence of absolute proof, finding the remains of their loved ones becomes a major preoccupation. Using a social phenomenological approach, this study explored the social and political complexities existing within the life-world of these women. The findings suggest that they live in a continual state of psychological distress and even when remains are returned, the unknown elements of the narrative of their abduction and murder only add to their distress and force many into self-imposed emotional exile away from community and close family.
\end{abstract}

Keywords: incomplete narratives, missing persons, ambiguous loss, abduction, Kosovo

Narrative as a means to make sense of the world has particular relevance to victims of ambiguous loss and bereavement. The importance of finding meaning in the events of everyday life involves ensuring that the important stories that constitute the life narrative are coherent, internally consistent and, most importantly, complete. Narrative thinking usually employs a plot, a theme and an object lesson (Bruner, 1986, 1990), but what happens when there is no object lesson, or when the outcome is ambiguous and details incomplete? Incomplete endings often generate endless speculation as plausible explanations for events or connections between events are sought in order to achieve correspondence and coherence (László, 2003). This is precisely the predicament of those who have lost a child who has never been found, and if presumed dead, have never come to know the truth about their last moments. What are the psychological and behavioural consequences of this incomplete bereavement narrative? In war torn countries, this scenario is all too familiar and Kosovo presents an important case study. 


\section{The political context}

At the end of the 1998-1999 war in Kosovo, thousands of men were reported missing to the authorities and their plight prompted the largest international forensic investigation in history: the exhumation of graves by the International Criminal Tribunal for the former Yugoslavia (ICTY) (Keough \& Samuels, 2004). The expectation of the families that their missing relatives would be found alive or they would receive their remains was, however, at odds with the mandate of the international forensic investigators, which was to uncover as much evidence as necessary for the prosecution of war crimes. This investigation was therefore not to be a full accounting of all the missing nor indeed were there resources to carry out such a task (Stover \& Shigekane, 2002). Moreover, to make matters worse for the families, information provided by Serbian military and intelligence officers indicated that the remains of approximately 1,500 ethnic Albanians had been completely destroyed in the north of Kosovo (Human Rights Watch, 2001) and given that the Serbian military had buried, exhumed and re-deposited remains many times in different locations to cover their tracks, it is no surprise that comingled remains in mass graves significantly hindered the task of identification (Williams \& Crews, 2003).

Disappearance has long been used as a means of political repression throughout the world (see Malin, 1993). It is usually accompanied by institutional denial, which has far reaching psychological consequences on the families of the missing. The perpetrators who bear responsibility for the missing escape justice even though they may be known and may continue to live an ordinary life. Given these circumstances, families of the missing are often unsure how to proceed. They may hold back through fear of provoking a negative reaction from the authorities, which they believe are responsible for the loss. Indeed, in countries where there has been a complete breakdown of traditional law and order, fear of reprisals, feelings of helplessness resulting in inaction and guilt, result in a period of obsessive searching (Amnesty International, 1981).

The term 'missing' can have multiple meanings for the families involved, it may not necessarily signal only the lack of a body, it also represents a missing personal history, the absence of an ending. Wagner (2008) notes that in the case of Srebrenica, the word 'missing' conjured up images of burial, exhumation and multiple reburial by the Serbian forces. It represented in the minds of the families not only the undead status of their relatives but also the likely criminal violation of their remains. 


\section{The psychological effects of disappearance}

The issue of loss is complex and multidimensional. We know that unsuccessful efforts to restore or maintain an affectionate bond often result in chronic distress (Bowlby, 1980). In this instance, the emotional strain for waiting relatives is particularly difficult because the missing person is a "child", which is arguably the worst possible bereavement experience (Young \& Papadatou, 1997). Furthermore, because the abduction was sudden, unforeseen and unpreventable, the disappearance lacks context; there was no anticipation, no build up or preparation and no opportunity to say good-bye or to resolve personal differences and, unlike an expected death, there is no transitional period of anticipation and acceptance (Parkes \& Weiss, 1983; Parkes \& Prigerson, 2010). Indeed, this type of loss presents a disintegration of an assumptive world in which a belief in an ordered physical and emotional world is brought to an abrupt end (Janoff-Bulman, 1992).

Associated with adaptive responses to loss is the process of making sense of the situation. Stroebe \& Schut, (2010) argue that the grieving process is an oscillation between loss oriented and restoration oriented stressors; where meaning is gradually achieved through greater oscillation towards restoration tasks. However, deriving meaning from abduction is difficult because there is no definitive information about the victim's demise or details about their final moments. The family is therefore unable to construct a coherent narrative sequence of events, which can be revisited over time to help move the grieving process along. In such cases, the family is left isolated and powerless, able only to make imaginary reconstructions of their final moments (Rynearson, 2001). Added to this, relatives of missing persons grieve twice: once for the physical loss of the person from their lives and again for the lack of a body over which to grieve (Edkins, 2011). In less complex cases, adaptive responses to loss may include the appropriation of a new identity that reflects the new reality resulting from death (Gillies \& Neimeyer, 2006). For mothers of missing persons, however, this is neither possible nor desirable: motherhood is a lifelong identity that does not end at death.

It is understandable that families of "the missing" often live in a perpetual state of shock and crisis (Amnesty International, 1981) and because no official information is forthcoming, the ambiguity is a source of chronic distress that can continue for decades (Boss, Beaulieu, Wieling, Turner \& LaCruz, 2003; Boss, 2007). For many married women, this state of limbo affects their social status and position in the community: 
Without a body to bury, without assurance of death, real grieving cannot even begin, because it is viewed as disloyal. This is not denial but reality. Without the certainty of death, the status of family members remains unclear. The women are not even widows, but widows waiting to happen, an agonizing role.

(Wiliiams \& Crews, 2003, p. 252)

\section{Ambiguous loss}

Two types of ambiguous loss have been identified; one where the body is missing and the person remains psychologically present and the other where someone is physically present but psychologically absent (Boss, 2002). Ambiguous loss is problematic insofar as it freezes the grieving process. Where there is a missing person in a physical sense, those waiting for news are prevented from coming to terms with the full reality of their loss, which may cause them to develop false hope rather than face the likely truth. In this context, loss is not clearly definable as death because there is no body to bury and the missing person is still psychologically present and part of a family. To add to the distress, the disappearance of a family member as a means of political repression or as a consequence of conflict is usually accompanied by longstanding institutional denial (see Malin, 1993) despite the mandate of the Geneva Convention, which requires states to assist with the process of locating and identifying remains. Under the Convention, families have the right to "know the fate of their relatives'.

Post conflict, attempts to rebuild lives on a personal level usually coincide with the recovery of the wider culture. However, rebuilding infrastructure and reintroducing the rule of law often overshadows the personal struggles that individuals have to face to rebuild their lives. A sense of confusion may persist in which the uncertainty created by the absence fosters a climate of personal indecision whereby important decisions cannot be taken. Roles, routines and family rules may also be frozen in time and the absence of a body also denies the family the social licence to grieve making it impossible to perform the religious or personal rituals, which can break down denial and allow the family to move through the grieving process (Boss, 2002; Betz \& Thorngren, 2006).

For there to be recovery, there has to be an intellectual acceptance of the loss. To achieve this, it is necessary to develop a rational narrative account of the events that led up to the death, which must answer essential questions for the bereaved to fully accept the outcome (Parkes \& Weiss, 1983). This task alone, however, is unlikely to be enough to complete the grieving process. An individual needs to establish a simultaneous balance between loss oriented and restoration oriented stressors. With time, there needs to be a shift away from loss and a move toward restoration (Stroebe, Schut \& Stroebe, 2005). Eventually, 
full acceptance should allow an individual to arrive at a point where the distress caused by the memory of the deceased no longer outweighs the pleasure of recollection.

The present study explores the current life-world of ten Kosovo-Albanian mothers who lost their sons (and in some cases husbands) during the war in Kosovo 1998-99. The aim is to outline some of the social, political and psychological issues that result from the ambiguity and uncertainty of their loss 13 years after the abductions.

\section{Method}

\section{Participants}

Ten Kosovo-Albanian women took part in the study and were contacted through two nongovernmental organizations that deal with the issue of resolving the fate of the missing from the 1998-1999 war. All participants had at least one son aged between 14 and 30 years taken from them. All the missing or deceased were civilians not involved in any form of resistance or rebel activity with the possible exception of one. All were abducted by Serbian forces apart from one, whose disappearance remains unclear. In the majority of cases, the boys and men were taken from their homes or the homes of relatives and neighbours in which they had sought refuge.

Mothers who had found their missing sons (pseudonyms provided)

Mothers Children

Bahrije one son

Durije two sons

Elfete two sons/two daughters

Sadije two sons/one daughter

\author{
Status \\ killed - found and reburied \\ older son killed - found and reburied \\ both sons killed - both found and reburied \\ husband and two sons killed - found and \\ reburied
}

\section{Mothers of the missing}

Mothers Children

\section{Status}

Besa one son/three daughters only son abducted - still missing

Drita three sons/one daughter youngest son abducted - still missing Fikrije four sons husband and four sons abducted - two found and reburied, husband and two sons still missing 
Ganimete three sons/two daughters

Lule two sons/two daughters two sons taken - one found and reburied - one still missing

one son taken - still missing

\section{Found then missing}

Mother

Children

Status

Kumrije one son/two daughters

only son killed - found and reburied

possible error of identification - exhumation likely

There were five distinct psychological circumstances:

(i) Mothers who had found and reburied their sons (five participants).

(ii) Mothers who were still searching for their sons' remains (four participants).

(iii) Mother who still believes her son is alive (one participant)

(iv) Mothers who had found and reburied some of their children, but had others who were still missing (two participants).

(v) A mother who had found and buried her son but who now faced the possibility of his exhumation due to an error of identification (one participant)

\section{The interviews}

The interviews were conducted over a period of two weeks during the spring of 2012 in Kosovo in the areas where the abductions and killings took place. The interviews were conducted in Albanian, the native language of the participants and the researcher. Semi-structured interviews explored the narrative circumstances of the disappearance or abduction from which it was possible to establish behavioural features of the grieving process and emotional perspectives that underpin their daily experience. Participants were eased into the interview process through gentle conversation ever mindful that we were asking them to discharge highly charged emotions connected to their family and political history. Once the participants were comfortable and psychologically prepared, the interview progressed to more specific questions. The interviews lasted between 17 and 60 minutes. The interview was divided into three sections: first, the mothers were asked to describe their son, i.e. "Tell 
me something about your son". The next section involved questions about the day their sons were taken and whether they thought they were still alive, whether they kept their belongings, how the manner of their son's death had affected them and how important it was for them to find their remains. The interviews were recorded and first transcribed in Albanian and subsequently translated and transcribed into English.

\section{Data analysis}

The textual data were subjected to a process of Interpretative Phenomological Analysis (IPA). The interviews were read in sequence, behavioural and emotional themes were identified. IPA allowed us to employ a dual interpretation process in exploring and interpreting the experiences of the participants using knowledge of the region and the events in question (Smith \& Eatough, 2006). The data were coded for semantic and latent meaning and codes were then grouped together under general themes. An inductive coding process was used in order to establish the main themes; this allowed the data to drive the research rather than having any pre-existing coding framework. Through a process of recoding and re-organising existing codes, the themes were reviewed, modified and condensed. The interview data were analysed independently by both authors: in the Albanian language by the first author and in the English language by the second.

The sensitivity of the subject matter and the complex regionally-specific cultural aspects of their experience meant that it was important for the interviews to be conducted by someone familiar with these events. The interviewer was a Kosovo Albanian national who had lived in Kosovo during the war and who, through field-work, had first-hand experience of the conflict. The interviewer had suffered no personal losses from the war and had no family members missing as a result of the war. A sense of shared ethnicity and experience promoted understanding and allowed communication to flow in such a way that participants were able to reveal their feelings without fear of being misunderstood.

A variety of locations were selected for the interviews during the two-week period to avoid the likelihood of mothers in each community discussing their interviews with each other. Interviews were conducted in three different towns: one in the north, west and south of the country.

\section{Findings}

The abductions 
In most cases, the mothers were present when their sons were taken from them. Events took place in March 1999, and a typical account is given by two women:

I remember the Serbs knocking on the neighbours gate, we thought that it would be better to open up the gate for them so that they would not lose their tempers and also we were not involved in anything. We had young boys who did not have any political affiliations; they did not even have ID cards.

(Sadije, Page 2, Line 79)

At the time my husband Shaip said, 'Don't be afraid, it's the police; they won't harm us'. (Fikrije, Page 1, Line 33)

This level of trust may be attributed to the high degree of familiarity, which is characteristic of Kosovo's small, tightly knit community. Some participants knew the police officers by their first names:

The people who took my family were familiar, they were not paramilitaries; they had eaten from my husband's hands. They wore the clothes that he had sewn.

(Fikrije, Page 8, Lines 13-14)

The first lot of police was familiar; one of them had worked at the palace of culture. My husband used to be the director of the professional theatre $[\ldots]$ and one of the policemen that came in used to be an amateur actor in the Serbian theatre. I used to know Dragan very well, I used to talk to him, when I saw him I said, 'Dragan! You?' They were all in uniform; all of them were regular citizens, workers. He replied to me in Serbian, 'Don't talk at all' and I didn't talk anymore.

(Ganimete, Page 1, Lines 29-

35)

To see their own neighbours turning on them was an additional trauma, and despite some knowing the police officers, the shock and fear of the situation induced a state of physical and mental paralysis:

I saw my boys looking at me but you seem to get lost completely in such moments. I didn't know anything, I was just shaking.

(Ganimete, Page 1, Lines 42-43)

As we were leaving the apartment I got completely lost; my husband was saying 'Put your boots on, put your boots on,' but when my sister said that they were dividing the men I got completely lost and I did not even know where I was.

(Elfete, Page 3, Lines 34-37) 
His (my son's) body became weak, I saw him but I couldn't say anything and he couldn't say anything back.

All protective instincts were overwhelmed by fear. As their sons were taken away, many feared that any attempt to interfere might cause their children harm. None acted to stop the abductions; they hoped that there was still a process of law at work within Kosovo that would protect their sons and ensure their subsequent release once their innocence had been established.

\section{States of mind}

As one would expect, all those involved experienced psychological distress during the period after the abductions: a state that led to intense searching behaviour. The uncertainty also gave rise to an incessant mental oscillation between the thought that the missing son or husband was dead and the immediate rejection of that thought. This dual state of mind was impossible to resolve and the prolonged stress of a dual existence, whereby the trauma of loss is experienced alongside the need to continue with daily life, was clearly taking its toll. From the testimonies of many of the women, their situation seemed to delay the grieving process because of the possibility that the missing person may be found alive, while on other occasions, grief reactions appeared to continue without end. It was no surprise then, that to resolve the difficulties cause by their mental state, a desire to die was a common theme:

My future is when I die, I go to God and then maybe I will be happy.

(Bahrije, Page 3, Line 32)

All I want is to find my son's body and put him to rest and then I can go and join them. That is where I see myself. I do not feel I need to contribute something for my other children or to be around in case they need me, not at all. All I want is to join them over there, I am only waiting to find my other son and bury him.

(Ganimete, Page 6, Lines 27-30)

For others, however, there was a feeling of intense need to keep living in order to complete the mission:

I pray to God to give me good health in my lifetime so that I can achieve my aim and bury them with my own hands.

(Fikrije, Page4, Line 32-33) 
Indeed, although death was often seen as a relief, one mother felt the need to keep living just in case her son returned. Her will to live was linked to her refusal to accept that he was dead:

Sometimes I wonder, 'Why am I still alive?' Morning, why are you opening on me? Nightfall why do you still find me? And then I think what if Visar comes back?

(Lule, Page 5, Line 45-46)

Another woman had been asked by the authorities to return her son's remains for more forensic testing. Her main motivation for continuing her life was to protect her son from exhumation.

This is not a peaceful life. For me I would like to go as soon as possible. On the other hand after all that they have done now I want to live as long as possible, to have my strength and health until this ends so that they do not touch my Sokol. I have asked God to join Sokol every day. Now I want a long life so that I can protect his body, so that they do not touch him again, because I go and talk to him.

(Kumrije, Page 11, Lines 40-45)

This woman was not able to protect her son when he was abducted, but once she had his remains, she found the strength to live and to fight. The grave became an important link to him and an indication that the mother-son bond had been reconnected.

\section{Incomplete narratives}

When remains were presented to the family, the physical reality of what had happened often incapacitated the mothers in a way that was reminiscent of the abductions. One reported that the uncertainty regarding the fate of her fourteen-year old son, was dwarfed by the pain of seeing the reality of his death:

I have seen them. Even just by the human skeleton you can tell which one is your child. With Bashkim, I could not hold him; his skull was split in three pieces. Besa took his skull and put it together. I couldn't do it then but I have a great regret that I did not hold him. Why did I not hold it? Why didn't I hold it? I have never mentioned this to anyone; I am only saying this to you. I have a big regret; why didn't I hold it? It pained me so much to see what they had done to him. Why didn't I hold him? Besa held him, looked at him and said, 'This is Bashkim'. I have a big regret but I have never said it to anyone. She took his head and held

it out to me but I froze and I couldn't. I regret it a lot but I can't turn back time. I regret it.

(Fikrije, Page 7, Lines 35-44) 
Although the ambiguity had now been resolved in this particular instance, the uncertainty about the way in which these young men died continued:

It affects me a lot. I think of how they were killed. I don't know what they have done to them.... I keep on thinking, 'Why the three of them at once?' I don't know how they were killed; was it with weapons? I wonder why? If they were ill I would have maybe made peace, but I cannot make peace with this. Why? How? Why kill my children when they were innocent? They did nothing wrong.

(Sadije, Page 5, Lines 10-16)

Ohhhh, as a mother I think all sorts of things. I think if when they killed him, had he asked for anything. I think of all sorts of things; I think how did it happen? He was not in the army; why him?

(Durije, Page 3, Lines 45-49)

God knows how his life ended; he was taken away. It is not easy not to know how his life ended. Was he tortured? These thoughts torture me every second.

(Kumrije, Page 4, Lines 15-16)

\section{Connection through clothes and personal items}

All the mothers reported that they had kept as many belongings of their missing children as they could and some used them to build shrines. Fikrije turned her home into an official museum to her lost loved ones, and both Besa and Kumrije dedicated rooms to their missing sons. These shrines helped to maintain a bond between them and their sons:

Yes, I have all of his clothes. Unfortunately they have taken all of his shoes. After the war I washed all his clothes. It was difficult to wash his clothes - to see them - but then I still hoped that they are still somewhere alive. I have them all folded; he has his own wardrobe; he has his watch, which he used to wake up with every morning. He has his clothes all folded. I often open his wardrobe and smell them...They are the memory of my son; they are the clothes that he wore. I will always keep them.

(Besa, Page 4, Lines 13-19)

When asked whether her son's belongings had been thrown away, Kumrije responded:

Not a single item. To tell you the truth even his rubber slippers that one wears in the yard and when one goes swimming I could not bin; they are ripped, they do not need to be kept but how can a mother bin them? It felt as if I am throwing him away just as those criminals did. I 
have kept everything, his shoes, his slippers, his clothes; they are just the way he left them. He has his own wardrobe, exactly the way he left it; I haven't touched it. I haven't thrown anything away. Every so often I change the photograph on his grave; I take away the one that has faded from the sun, snow, rain but I cannot throw it away; I keep it. I have made an album that is only his. I have collected all the photographs since he was a baby until the day he was buried. All of these photos I keep in an album, I save them, I cannot throw those photos even though you cannot see anything; they have faded, they look just like this [blank] paper.

(Kumrije, Page 5, Lines 41-50)

Clothes were a physical representation of the missing person, and the belongings and photographs, to which she assigned so much importance, had become something whose fate she could control.

Drita, who was still searching for her son, had only a pair of his underpants in her possession, which represented a sense of longing:

Luckily I have kept a pair of his underpants. From the yearning that I have for him I have put them under the pillow where I sleep. I keep them under my pillow, his underpants, I keep them under my pillow. Those underpants are all that I have left, everything else they have taken, nothing was left in the flat...I have pictures. I tried it [sleeping] with the pictures because I have a lot of them. I have tried it with the pictures and with the underpants, I used to think that maybe I will dream of him...

(Drita, Page 4, Lines 30-37)

In one instance where the deceased had been found and buried, some of the clothes were worn by relatives:

We still keep their belongings; my daughter likes to keep them; we do keep them all. I have given a few of their shirts to my brother; I like it when I see him wearing them. Some people do not like doing things like that but I do; it reminds me of my children and I think, 'This is what my younger son used to wear and now my brother wears it'. I wear their clothes too, they remind me of them; it feels like they are around me.

(Sadije, Page 3, Line 50 - Page 4, Line 5)

\section{An end to ambiguity}

All the mothers interviewed (except for one who saw her son's body within days of his death) had hoped that their sons were still alive, but this was often in the face of overwhelming circumstantial evidence. Many only began to accept that they were dead when presented 
with physical remains; and those who experienced this at an earlier stage were now more at peace:

The night we buried them it felt as if I had found them alive, I found peace, as if I had found them alive.

(Elfete, Page 8, Lines 15-16).

It is very important because there is nothing you can do anymore once you know their fate. Once you know what happened, there is nothing you can do anymore and you come to terms with that. When you are sad you go, you cry, maybe even just stay there without crying; only look at his picture. I have the same pictures at home as well but when I go there I feel like I am talking to him; I feel he is alive; I feel he is looking at me straight in the eye and listening as I talk to him. That same photo is at home as well but when I see his grave I feel he is talking to me.

(Kumrije, Page 6, Lines 16-22)

As one would expect, a grave creates a physical reconnection between mother and son, as well ending the ambiguous loss. A grave seemed to have a calming effect. Often the mothers would devote a specific part of their day to the grave. Rather than consuming their every waking hour, their grief was now part of a daily routine or ritual:

We wake in the morning, we cry, have a coffee and go to the graves, we cry.

(Bahrije, Page 2, Line 28)

I go to the graves, sometimes I even go twice and when I get back I feel much lighter.

(Durije, Page 4, Lines 48-49)

Once they were able to make grieving part of their routine, the women were able to normalise other aspects of their lives. After years of neglecting her daughter and deliberately making her feel inferior to her brothers and making her feel guilty for her own survival, Sadije reported that coming to terms with the death of her two sons enabled her to acknowledge and recognize past deficiencies:

I used to say things to her, I used to say that I did not want to know about her and that I

wanted my boys. I wasn't myself then; I would not do that to her now.

(Sadije, Page 4, Lines 15-16)

What has changed in me is that now I am able to pay more attention to my daughter, as I told you earlier I did not give her much attention before. I was thinking about them all the time, I did not know where they were, I knew they were dead but until I got the bodies back... until they 
returned home. That is what has changed in me. Now I am oriented towards my daughter because she has gone through a lot, and what was worse I did not pay her any attention at all.

(Sadije, Page 5, Lines 22-27)

The end of ambiguity caused an important psychological shift as the mothers' hopes and aspirations were able to move from the dead to the living:

I see myself as stronger, I want my younger son to finish university, get married, I just want to see my son married and then even if I die I don't mind.

(Durije, Page 4, Lines 28-29)

On the other hand, those mothers who were still waiting for news longed for an end to the uncertainty:

My soul will find peace. I will know that his body does not rest in the places of the criminals in Serbia, or it doesn't rest in the morgue but it will come back just as his friends did.

(Besa, Page 6, Lines 43-45)

This is what is important now, to find them, to know what Serbs did to them otherwise we lose all trace. When you have a trace, there is a grave, you know the date when they were taken, the date when they were returned and the date of the funeral; you have three dates there.

(Fikrije, Page 4, Lines 34-37)

\section{The authorities: a source of distress}

The mothers' relationship with the authorities was often difficult and complex. Three structures of authority were involved in the loss and recovery of their children; the Serbian state that ordered the police and army units into the homes of Kosovar civilians; the international community that led the search for the remains of the missing and retained authority in Kosovo during the post war years and the local authorities that took over governmental authority in Kosovo after the declaration of independence in 2008. Each has had a profound effect. The dominant view was that, 13 years after the war, justice had still not been done. They also felt that any punishments that had been meted out were inadequate and disproportionate to the gravity of the crimes committed. Nonetheless, the mothers expressed no hatred towards the individuals who carried out the crimes, nor did they seek revenge even though many were known to them. Rather, their anger was directed at the state apparatus that organised the killings: 
Now all we want is to punish the people for committing the crimes, forgiveness does not calm your spirit. They need to be punished as a state and not only the criminals; they did not commit the crimes on their own. It was the regime, the state that gave the orders to commit the crimes. They do not get punished, not a single one gets caught.

(Kumrije, Page 7, Lines 24-28)

At the cessation of hostilities, authority in Kosovo was transferred from Serbia to the international community upon whom the mothers depended to determine the fate of their missing sons. The brief period of hope and belief that accompanied their arrival eventually turned to one of despair and mistrust. For example, one participant explains:

Since the end of the war in 1999 we have taken part in protest after protest, hunger strikes. We have been to every Kosovo institution, UNMIK and EU-LEX. They all say we will see, we will see, we will see but until today nothing.

(Fikrije, Page 2, Lines 37-39)

Most of the mothers did not trust the new authorities since it was evident these organisations were working to an agenda that did not include full identification of all the victims. They were therefore largely perceived as ineffective and, at times, incompetent. One mother was even asked to return the remains of her son after the forensic team realised they had made a mistake in the identification process:

I told them 'you are insane, you are not even slightly concerned about the families, you are torturing the bodies of these young boys that were once tortured by the Serbs; you are acting same way as they did. This is a multiple murder'. They have killed them, carried them around, have found them, exhumed them, returned them and now they want to take them once more! What for? They have released the documentation, they have come to me and said that my son has been identified and asked if accept to take him. I accepted because you have identified him. How can they release documentation they have no basis for? How do they make me sign without any basis?

(Kumrije, Page 9, Lines 23-30)

She continued: 
Another mother expressed a similar sentiment. Speaking of the international authorities in charge of exhumations, she exclaimed:

They kill us every day, international institutions kill these families every day.

(Lule, Page 5, Line 22)

The intense frustration and dissatisfaction was largely due to their lack of control over proceedings. Compared to traditional methods of identification where relatives would examine clothes and belongings of the deceased, the scientific nature of modern identification methods using DNA testing excluded relatives from the process. Their mistrust in the identification process and their disappointment in the foreign forensic specialists with whom they had no cultural or linguistic ties, continued after Kosovo became an independent state in 2008.

Although the foregoing paints a rather grim picture of daily existence, there were, however, one or two anecdotes bearing testimony to the sensitivity of people in the community. One mother described the way in which a woman in her locality would always avoid parading her family in front of her. Others reported small kindnesses that were a help: a kind word was always appreciated. These small and almost insignificant acts helped them get through the day.

\section{Conclusions}

These testimonies are the forgotten consequences of ethnic conflict. As we seek to understand global politics, there may be a tendency to intellectualise 'collateral damage' as an unavoidable consequence of war, rather than confront its human cost. Indeed, the cost of ethnic conflict often extends beyond widespread death; conflict causes a more extreme form of suffering that is prolonged and debilitating. This paper has highlighted the plight of relatives of 'the missing' in Kosovo and the uncertainty and ambiguity associated with their loss and the testimony given by this group (and many others like them) is one that requires our full attention and understanding.

We need to remind ourselves that a capricious event such as a sudden and violent death cannot be theorized as if it were the consequence of some universal system (Rynearson, 2001). What is more, the social and psychological effects likely vary among individuals and cultures so this study makes no attempt to establish or endorse universal patterns of grief. We thus attempt only to document, describe and categorise the thoughts, behaviours, 
reactions and social consequences experienced by these women in an attempt to establish themes that allow us to recognise and address their specific difficulties.

The sudden and unforeseen abduction of their sons was the result of a process of ethnic cleansing that was a bewildering mix of state brutality and complicit actions carried out by willing neighbours and former colleagues; and particularly within a culture that esteems the male as 'son and heir' is this type of loss profound and painful. This desire to find the remains is so overwhelming that it often eclipses relationships with surviving children with whom some report a lack of connection and sense of parental responsibility; a reminder that replacement or displacement is no compensation for loss.

Their continual preoccupation with thoughts of their missing children and their lack of progress in coming to terms with their situation prolongs their distress, and without the restorative power of certainty, they often descend into a self-imposed emotional exile from close family and the wider culture. The psychological/physical connection maintained through clothes and personal possessions (see Volkan, 1972; Jurcevic \& Urlic, 2002), accompanies an incessant internal dialogue that advocates acceptance of death in one breath and rejection of it in another. The rapid cycling emotions that result are difficult to deal with for all concerned.

The social consequences of their loss are also considerable. Although many were only in their 50s when interviewed, little sense of future was expressed and most appeared to be 'going through the motions'. Even those who have daughters and grandchildren acknowledge that their psychological state disrupts family dynamics. What is more, the pain intensifies for those deprived of grandchildren as they watch the families of their contemporaries grow and mature. In Kosovo, no news about the missing is bad news and when news does arrive, it is seldom cause for rejoicing. In such confusing and ambiguous circumstances 'finding the missing' takes on more than one meaning and because hope is an integral part of the human spirit, the emotional state of those who wait for news can never be assumed or taken for granted. In this regard, we are reminded of one mother who was told that her son had been found. Overwhelmed with emotion, she danced for joy. She had, however, misunderstood; they had found him dead.

\section{References}

Amnesty International. (1981). Disappearances: A workbook. New York: Amnesty International USA.

Betz, G. \& Thorngren, J. M. (2006). Ambiguous loss and the family grieving process. The Family Journal: Counseling and Therapy for Couples and Families, 14, 359-365.

Boss, P. (2002). Ambiguous loss in families of the missing. The Lancet Supplement, 360, 39- 40. 
Boss, P., Beaulieu, L., Wieling, E., Turner, W., LaCruz, Sh. (2003). Healing loss, ambiguity and trauma: A community-based intervention with families of union workers missing after the 9/11 attack in New York city. Journal of Marital and Family Therapy, 29, 455-467.

Boss, P. (2007). Ambiguous loss theory: Challenges for scholars and practitioners. Family Relations, 56, 105-111.

Bruner, J. (1986). Actual minds, possible worlds. Cambridge, MA: Harvard University Press.

Bruner, J. (1990). Acts of meaning. Cambridge, MA: Harvard University Press.

Edkins. J. (2011). Missing persons and politics. Ithaca, NY: Cornell University Press.

Gillies, J., \& Neimeyer, R. A. (2006). Loss, Grief, and the Search for Significance: Toward a Model of Meaning Reconstruction in Bereavement. Journal of Constructivist Psychology, 19, 31-65.

Human Rights Watch. (2001). Under orders: war crimes in Kosovo. New York.

Jurcevic, S., \& Urlic, I. (2002). Linking objects in the process of mourning for sons disappeared in war: Croatia 2001. Croatian Medical Journal, 43, 234-239.

Keough, M. E., \& Samuels, M. F. (2004). The Kosovo family support project: Offering psychosocial support for families with missing persons. Social Work, 49, 587-594.

László, J. (2003). History, identity and narratives. In J. László, \& W. Wagner (Eds.), Theories and controversies in societal psychology (pp. 180-192). Budapest, Hungary: New Mandate.

Malin, A. (1993). Mother who won't disappear. Human Rights Quarterly, 15, 187-213.

Parkes, C. M. \& Prigerson, H. G. (2010). Bereavement: Studies of grief in adult life. London: Penguin Books.

Parkes, C. M. \& Weiss, R. S. (1983). Recovery from bereavement. New York: Basic Books.

Pedersen, D. (2002). Political violence, ethnic conflict, and contemporary wars: broad implications for health and social well-being. Social Science \& Medicine, 55, 175-190.

Robben, A. (2000). The assault on basic trust: Disappearance, protest and reburial in Argentina. In A. Robben \& M. Suarez-Orozco (Eds.), Cultures under Siege: Collective Violence and Trauma. (pp. 70-101). Cambridge: Cambridge University Press.

Rynearson, E. K. (2001). Retelling violent death. New York: Routledge.

Smith, J. A. \& Osborn, M. (2015). Interpretative Phenomenological analysis. In J. A. Smith (Ed.), Qualitative Psychology: A Practical Guide to Research Methods (3 ${ }^{\text {rd }}$ ed.) (pp.25-53). London: Sage.

Stover, E. \& Shigekane, R. (2002). The missing in the aftermath of war: When do the needs of victims' families and international war crimes tribunals clash? IRRC December, 84, 845-865.

Stroebe, M., Schut, H., \& Stroebe, W. (2005). Attachment in coping with bereavement: A theoretical integration. Review of General Psychology, 9, 48-66.

Stroebe, M. \& Schut, H. (2010). The dual process model of coping with bereavement: A decade on. Omega 61(4), 273-289. 
Volkan, V.D. (1972). The linking objects of pathological mourners. Archives of General Psychiatry, $27,215-221$.

Wagner, S. E. (2008). To know where he lies: DNA technology and the search for Srebrenica missing. Berkley and Los Angeles: University of California Press.

Williams, E. D. \& Crews, J. D. (2003). From Dust to Dust: Ethical and Practical Issues Involved in the Location, Exhumation, and Identification of Bodies from Mass Graves. Croatian Medical Journal, 44(3), 251-258.

Young, B. \& Papadatou, D. (1997). Childhood death and bereavement across cultures. In C. M. Parkes, P. Laungani, \& B. Young (Eds.), Death and bereavement across cultures. (pp. 191205). London. 